\title{
Ecological Observations on Hybrid Populations of European Plethodontid Salamanders, Genus Speleomantes
}

\author{
Enrico Lunghi ${ }^{1,2,3,4, *(\mathbb{D})}$, Fabio Cianferoni ${ }^{2,5} \mathbb{D}$, Stefano Merilli ${ }^{6}$, Yahui Zhao ${ }^{1, *(\mathbb{D}}$, Raoul Manenti ${ }^{7,8} \mathbb{D}$, \\ Gentile Francesco Ficetola $^{7,9}$ (D) and Claudia Corti ${ }^{2}$
}

check for updates

Citation: Lunghi, E.; Cianferoni, F.; Merilli, S.; Zhao, Y.; Manenti, R.; Ficetola, G.F.; Corti, C. Ecological Observations on Hybrid Populations of European Plethodontid Salamanders, Genus Speleomantes. Diversity 2021, 13, 285. https:// doi.org/10.3390/d13070285

\section{Academic Editors:}

Salvidio Sebastiano and

Michael Wink

Received: 25 May 2021

Accepted: 17 June 2021

Published: 23 June 2021

Publisher's Note: MDPI stays neutral with regard to jurisdictional claims in published maps and institutional affiliations.

Copyright: () 2021 by the authors Licensee MDPI, Basel, Switzerland. This article is an open access article distributed under the terms and conditions of the Creative Commons Attribution (CC BY) license (https:// creativecommons.org/licenses/by/ $4.0 /)$
1 Key Laboratory of the Zoological Systematics and Evolution, Institute of Zoology, Chinese Academy of Sciences, Beichen West Road 1, Beijing 100101, China

2 Museo di Storia Naturale dell’Università di Firenze, Museo "La Specola”, Via Romana 17, 50125 Firenze, Italy; cianferoni.fabio@gmail.com (F.C.); claudia.corti@unifi.it (C.C.)

3 Natural Oasis, Via di Galceti 141, 59100 Prato, Italy

4 Unione Speleologica Calenzano, Piazza della Stazione 1, Calenzano, 50041 Firenze, Italy

5 Istituto di Ricerca sugli Ecosistemi Terrestri (IRET), Consiglio Nazionale delle Ricerche (CNR), Sesto Fiorentino, 50019 Firenze, Italy

6 Speleo Club Firenze via Guardavia 8, 50143 Firenze, Italy; s.merilli@virgilio.it

7 Department of Environmental Science and Policy, Universitòà degli Studi di Milano, Via Celoria, 26, 20133 Milan, Italy; raoulmanenti@gmail.com (R.M.); francesco.ficetola@gmail.com (G.F.F.)

8 Laboratorio di Biologia Sotterranea "Enrico Pezzoli", Parco Regionale del Monte Barro, 23851 Galbiate, Italy

9 Université Grenoble Alpes, Université Savoie Mont Blanc, CNRS, LECA, Laboratoire d’Ecologie Alpine, F-38000 Grenoble, France

* Correspondence: enrico.arti@gmail.com (E.L.); zhaoyh@ioz.ac.cn (Y.Z.)
Abstract: Speleomantes are the only plethodontid salamanders present in Europe. Multiple studies have been performed to investigate the trophic niche of the eight Speleomantes species, but none of these studies included hybrid populations. For the first time, we studied the trophic niche of five Speleomantes hybrid populations. Each population was surveyed twice in 2020, and stomach flushing was performed on each captured salamander; stomach flushing is a harmless technique that allows stomach contents to be inspected. We also assessed the potential divergence in size and body condition between natural and introduced hybrids, and their parental species. Previously collected data on Speleomantes were included to increase the robustness of these analyses. In only 33 out of 134 sampled hybrid Speleomantes we recognized 81 items belonging to 11 prey categories. The frequency of empty stomachs was higher in females and individuals from natural hybrid populations, whereas the largest number of prey was consumed by males. We compared the total length and body condition of 685 adult salamanders belonging to three types of hybrids and three parental (sub)species. Three group of salamanders (one hybrid and two parental species) showed significantly larger size, whereas no difference in body condition was observed. This study provided novel ecological information on Speleomantes hybrid populations. We also provided insights into the potential divergence between hybrids and parental species in terms of size and body condition. We discuss our findings, and formulate several hypotheses that should be tested in the future.

Keywords: Speleomantes; Hydromantes; trophic niche; body condition; cave biology; biospeleology; parental species; diet; size; capture-mark-recapture

\section{Introduction}

European cave salamanders of the genus Speleomantes are the only plethodontids living in the Europe, and are almost all endemic to Italy [1]. Seven of the eight Speleomantes species (S. ambrosii, S. italicus, S. flavus, S. supramontis, S. imperialis, S. sarrabusensis, S. genei) live exclusively in Italy, while the range of one species (S. strinatii) extends to part of French Provence [1]. Each species is distributed in a well-defined area, and no range overlap exists; Speleomantes distribution is likely shaped by geomorphology $[2,3]$. For $S$. 
ambrosii, the river Magra marks the separation of the two allopatric subspecies: the western S. ambrosii ambrosii and the eastern S. a. bianchii $[1,4]$. Although some phenotypic variability can be observed among Speleomantes [5-7], a valid method to phenotypically distinguish among species/subspecies is still lacking, thus their identification is based mostly on geography [1,3]. The southern distribution of the latter reaches the norther limit of $S$. italicus, creating a narrow contact zone in which viable hybrid populations are found $[1,8]$ (see Figure 1 of Ref. [8]) These natural hybrid populations exhibit some genetic divergence, which is mainly influenced by the relative abundance of individuals of each parental species: in the northern part of the range there are populations of $S$. a. bianchii introgressed with S. italicus, whereas in the southern area, the opposite occurs [8]. However, hybrids do not show a clear divergence of phenotypic characters from their parental species; therefore, hybrids can also only be recognized on the basis of their geographic distribution [8,9]. In addition to this natural hybrid zone, hybrids between $S$. ambrosii and S. italicus are also related to a human-mediated translocation. In 1983, for scientific purposes individuals of both $S$. italicus and $S$. a. ambrosii were introduced into a natural cave in southern Tuscany, outside the natural range of Speleomantes [1,10]. Thirty years after its introduction, the population was genetically characterized and none of the individuals had a pure genotype. For $77 \%$ of individuals, the majority of alleles $(>75 \%)$ matched alleles specific to $S$. $a$. ambrosii; for $6 \%$ of individuals, the majority of alleles matched those of $S$. italicus; and for $16 \%$ of individuals, alleles of S. a. ambrosii and of S. italicus were recombined [11]. However, the lack of ecological information on this population prevents us from evaluating the potential difference between these non-natural hybrids and the hybrids living in the natural hybrid zone, and to assess the trophic relationships between these populations and the local fauna $[8,12]$. Here we provide the first assessment of the size, body condition, and diet of both natural and introduced hybrid populations of Speleomantes.

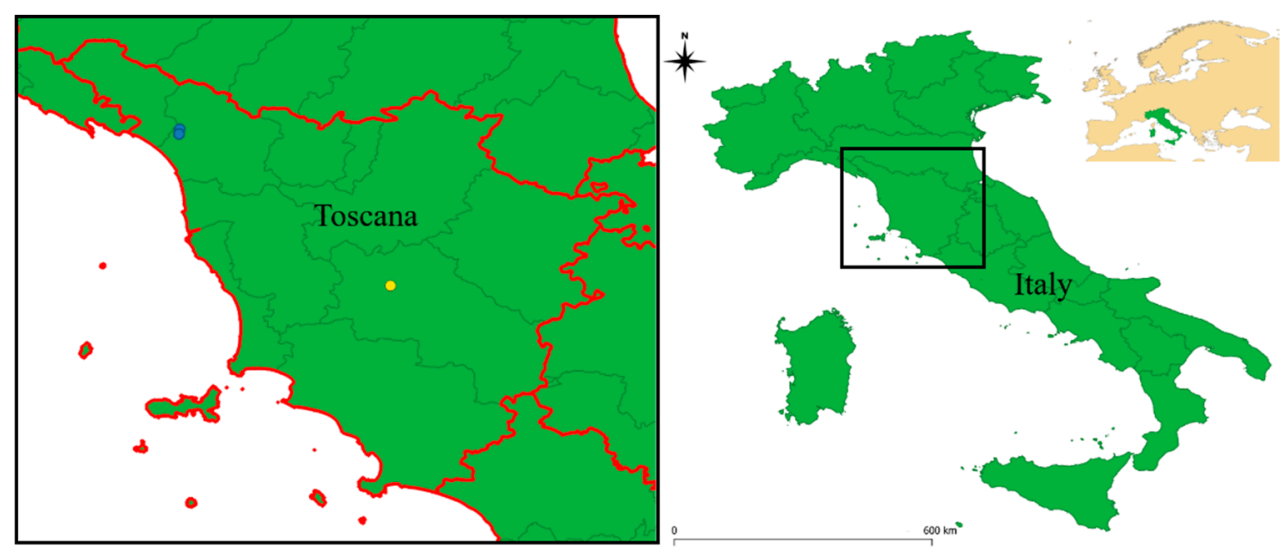

Figure 1. Map indicating the sampled populations. Blue labels indicate natural hybrid populations, whereas yellow indicates those introduced outside the natural distribution of Speleomantes. The coordinates of the surveyed sites are not provided to increase species protection [13].

\section{Materials and Methods}

In 2020 we surveyed five hybrid populations of Speleomantes that inhabit natural caves (Figure 1); each population was surveyed twice, once before (29 June-14 July) and after (3-10 September) the aestivation period [1].

Three populations are located within the natural hybrid zone between $S$. italicus and $S$. ambrosii bianchii occurring in north-western Tuscany (Province of Lucca); two populations included introgressed $S$. italicus with $>10 \%$ of $S$. ambrosii alleles, whereas the other is a $S$. ambrosii population introgressed with $>10 \%$ of $S$. italicus alleles [8]. The natural hybrid populations were selected following the genetic characterization of Ruggi, Cimmaruta, Forti and Nascetti [9]. The two other hybrid populations are found in southern Tuscany (Province of Siena), where cave salamanders are not native and have been introduced [1]. 
One of these two populations was discovered during this study. In the surroundings of the cave where Speleomantes were introduced [10], some authors (CC, EL, SM) have found and explored another cave about $53 \mathrm{~m}$ in a straight line from the previous one; because several Speleomantes were observed during the exploration, the individuals from this second cave were considered to be an additional population [14]. Surveys and animal handling were performed by taking measures to avoid the spread of pathogens (i.e., using disposable gloves and disinfecting boots and equipment after each survey). During each survey, all captured salamanders were placed in a perforated plastic box $(60 \times 40 \times 20 \mathrm{~cm})$. After salamanders were captured, we recorded the following data in sequence: individual sex (males were recognized by the presence of the distinctive mental gland, females were salamanders with SVL $\geq 40 \mathrm{~mm}$ without the mental gland, and remaining salamanders were considered juveniles) [1]; weight (using a digital scale, $0.01 \mathrm{~g}$ ); a photo was taken from the dorsal view of individuals positioned along a reference card [6]; the harmless stomach flushing technique was used to evaluate Speleomantes foraging activity [15]. All salamanders were released at their collection points. The photos were analyzed with ImageJ software to measure the total length (TL) of the salamanders and estimate the snoutvent length (SVL) [16]. Stomach contents were preserved in a $75 \%$ ethanol solution and subsequently observed under an optical microscope, where prey items were recognized and counted following [17]. When we were unable to recognize any item at the order level, we considered the content as "unidentifiable"; when no remains were found, the stomach was considered "empty". The dorsal pattern of salamanders was used for individual recognition [18].

We used binomial Generalized Linear Mixed Models (GLMMs) to assess the potential effects that the considered variables may have on the stomach condition. Four individuals were captured twice, so we only used data from their first capture. We used stomach condition (empty/full) as the dependent variable, and the independent variables were salamander sex (male, female, juvenile) and hybrid identity (natural = S. a. bianchii $\times S$. italicus; introduced $=S$. a. ambrosii $\times$ S. italicus); because the frequency of empty stomach changes over time [19], the survey month was added, together with the identity of the cave, as a random variable. Similarly, we used a GLMM to assess the potential correlation between the number of recognized prey and the independent variables mentioned above; cave and individual identity were still used as random variables.

We also performed a comprehensive analysis by combining these data with previously published datasets $[5,8,20]$ to evaluate differences in size and body condition between hybrids and parental species. In these previous studies, the threshold to discriminate between adults and juvenile was set on the base of the smallest TL measured among males, which was $69 \mathrm{~mm}$; in this study the smallest male had a SVL of $44 \mathrm{~mm}$ and TL of $69 \mathrm{~mm}$. For each site, only the survey with the highest number of measured salamanders was considered, with the exception of hybrid data, in which pattern recognition [18] allowed the inclusion of individuals captured for the first time during the second survey. We used a Linear Mixed Model (LMM) to evaluate the potential differences in adult size (TL) between different groups of salamanders (S. a. ambrosii, S. a. bianchii, S. italicus, S. a. ambrosii $\times$ S. italicus, S. a. bianchii $\times$ S. italicus). A Shapiro-Wilk test showed a non-normal distribution of data related to Speleomantes size (log-transformed TL, $\mathrm{W}=0.98, p<0.001$ ); however, LMM is appropriate for the analysis of non-normal distributed data [21]. The log-transformed TL was used as a dependent variable, and the group of salamanders as the independent variable. Considering the natural divergence in maximum size occurring between males and females [1], the sex of salamanders was used as a random factor. We used the Residual Index (RI) as a proxy of the body condition of the salamanders; this index provides information on the difference between the observed and the expected body mass [22,23]. To calculate the RI, we first log-transformed weight and TL, and then extracted residuals from the regression analysis for each species/hybrid group, in order to avoid bias due to different size [22,23]. Speleomantes body condition peaks during the foraging periods (i.e., when precipitation is higher and temperature relatively cold), and is 
poorest during inactivity periods (i.e., when climatic conditions are too hot and dry), when the salamanders mostly consume energy that was previously stored $[1,24,25]$. Therefore, in this analysis we only used data collected before the aestivation period (June-July). We used an LMM to assess the potential correlation between the RI (dependent variable) and two independent variables: the sex of the salamanders and the species group. Considering that data were collected over different periods, we included the month and year of the survey, in addition to the identity of the cave, as random factors. The significance of GLMM and LMM variables was tested with a likelihood ratio test.

\section{Results}

In the hybrid populations, we obtained 138 salamander detections corresponding to 134 individuals; four individuals (one male and three females) were observed twice. The size of the recaptured individuals (both SVL and TL) did not change between the two surveys: the difference between the first and second measurement was $<2 \mathrm{~mm}$; this difference is comparable to measurement error [16]. Most of the individuals sampled (90) had an empty stomach. The frequency of empty stomachs was significantly different between sexes $\left(\chi^{2}=7.31, \mathrm{df}=2, p=0.026\right)$ and type of hybrid $\left(\beta=4.41, \mathrm{SE}=1.14, \chi^{2}=14.91\right.$, $\mathrm{df}=1, p<0.001)$; the frequency of empty stomachs was higher in females and individuals from natural hybrid populations. Eleven individuals had stomach contents in a state of advanced digestion and, therefore, the contents were considered not identifiable. We were able to recognize a total of 81 prey items from 33 individuals; the recognized prey belonged to 11 different categories: Sarcoptiformes (1), Mesostigmata (1), Araneae (4), Pseudoscorpiones (4), Polydesmida (3), Isopoda (8), Hemiptera (1), Hymenoptera (1), Coleoptera (3), Coleoptera_larva (1), and Diptera (55). Diptera were the most consumed prey: they were observed in 32 individuals, representing $67 \%$ of recognized prey. The number of prey consumed was significantly affected by the sex of salamanders $\left(\chi^{2}=10.74\right.$, $\mathrm{df}=2, p=0.005)$; the largest number of prey was consumed by males.

When we combined the data of hybrid populations with those from previous surveys, we obtained data on the size and body condition of 678 salamanders (additional details in Figure 2). The maximum and average ( \pm SD) size (TL) measured for the salamander groups considered were: S. a. ambrosii, females max. 125 and average $91( \pm 14) \mathrm{mm}$, and males max. 105 and average $92( \pm 6) \mathrm{mm}$; S. a. bianchii, females max. 114 and average $89( \pm 12) \mathrm{mm}$, and males max. 124 and average $105( \pm 12) \mathrm{mm}$; S. italicus, females max. 120 and average $94( \pm 13) \mathrm{mm}$, and males max. 118 and average $101( \pm 8) \mathrm{mm}$; S. a. bianchii $\times$ S. italicus, females max. 119 and average $90( \pm 15) \mathrm{mm}$, and males max. 119 and average $95( \pm 8) \mathrm{mm}$; S. a. ambrosii $\times$ S. italicus, females max. 134 and average $98( \pm 20) \mathrm{mm}$, and males max. 108 and average $103( \pm 2) \mathrm{mm}$. The size of the adult salamanders significantly differed between the groups $\left(\mathrm{F}_{4,506}=4.61, p=0.001\right) ;$ S. italicus, S. a. bianchii, and S. a. ambrosii $\times$ S. italicus hybrids had the largest size (Figure 2). No significant differences in body condition were observed between sexes $\left(\mathrm{F}_{2,641}=0.69, p=0.5\right)$ or species groups $\left(\mathrm{F}_{4,25}=0.16, p=0.956\right)$. 


\section{Size of adult Speleomantes}

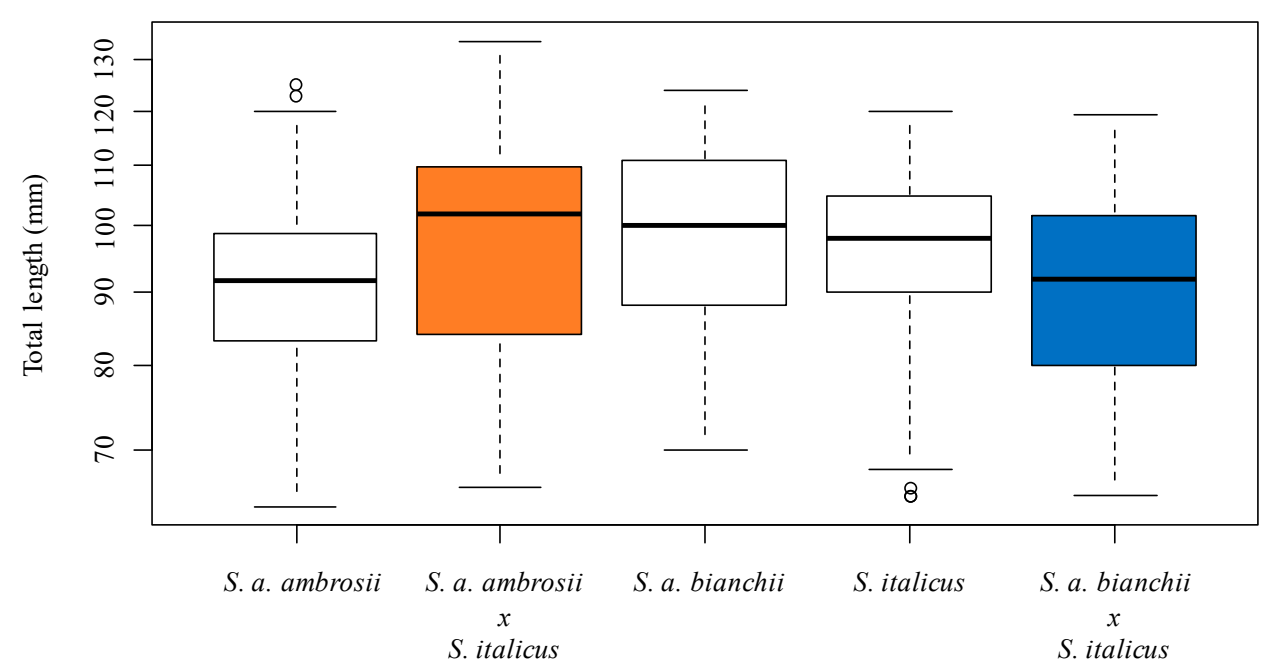

Figure 2. Boxplots showing the average size (TL) of adult Speleomantes considered in this study: S. $a$. ambrosii (163), S. a. ambrosii $\times$ S. italicus hybrids (28), S. a. bianchii (46), S. italicus (150), S. italicus $\times$ S. a. bianchii hybrids (125). The red box indicates introduced hybrids, blue natural hybrids, while in white the parental species.

\section{Discussion}

Studies on hybrid populations of Speleomantes have been extremely limited [8,11], leaving their morphological and ecological traits largely unknown. Despite our limited sample size, especially in regards to diet, we were able to obtain interesting information to provide the basis for future research. For example, we provide the first documentation relating to the natural colonization of a new environment performed by the introduced Speleomantes. Forty years after their release [10] the salamanders managed to occupy at least a nearby subterranean environment with a stable population. It is therefore of great importance to regularly monitor these hybrid populations to see if they will continue to extend their distribution.

The trophic niche of Speleomantes is subject to temporal variations $[19,26]$ and is therefore strongly influenced by the fluctuating availability of potential prey [27]. With this study we were able to gather only limited information on the diet of Speleomantes hybrids. Most of the prey consumed were Diptera, which can be highly abundant near the entrance of subterranean environments, especially during the hot season [28,29]. This is in agreement with previous studies on the Speleomantes diet [16,30,31]. We also observed generally higher male foraging activity, whereas natural hybrids appear to forage less. Natural hybrids are distributed in a small area of the Apuan Alps (north-western Tuscany), a territory characterized by different lithology and vegetation compared to that of other studied salamanders $[1,32,33]$. Diverging environmental characteristics may offer different prey availability or simply alter the peak of foraging activity in these Speleomantes populations $[24,27]$. Therefore, further and prolonged investigations on multiple hybrid populations are needed to better delineate their trophic niche [17], evaluate potential divergences $[27,30]$, and evaluate whether they increase foraging opportunities by expanding their microclimatic niche.

A further limitation of this study is the lack of genetic information on hybrid Speleomantes populations. Hybrid populations can undergo complex evolutionary phenomena, for example, with selective advantages for some components of their genome. To date, the available information on the genetic characteristics of hybrid populations is limited to allozyme data, which cannot capture the complexity of genomic processes [8]. Collecting genome-wide information on salamanders is challenging because their very large genome size makes the application of different genomic tools, such as RAD sequencing, problem- 
atic. However, recent developments can allow more affordable analysis of genome-wide variation, even in species with large genomes, and in the coming years this could improve our understanding of evolutionary processes affecting these populations [31,32].

In this study we observed larger size in introduced hybrids (S. a. ambrosii $\times$ S. italicus), S. italicus, and the S. a. bianchii subspecies. We do not have data on the potential genetic effect on the size of hybrid populations. However, ecological conditions are more likely to play an important role in driving the evolution of this adaptive trait. It has been shown that Speleomantes are in thermal equilibrium with their surrounding environment, and that larger individuals require more time to thermoconform, and are thus potentially able to exploit a less suitable microclimate for a longer period [8,20,33], allowing them to extend their activity period and increase foraging [24]. The larger size observed in introduced hybrids may be the result of a warmer and drier local climate, whereas the smaller size of natural hybrids may have been determined by the local colder and moister climatic conditions. This remains a hypothesis that deserves further investigation. Furthermore, introduced hybrids showed a lower frequency of empty stomachs compared to other population; thus, it is possible that higher food availability allows for better feeding and growth. However, this hypothesis is not supported by the lack of differences in the body condition index. Considering the larger size of the introduced hybrids (and the associated better tolerance of harsher conditions), we recommend regular monitoring of these populations to better control their range expansion, especially in the context of global warming [34,35].

Author Contributions: E.L. conceived the study, analysed the data, and prepared the figures; E.L., S.M., R.M., G.F.F. and C.C. performed field surveys; E.L. and F.C. performed the recognition of stomach contents; E.L., F.C., S.M., Y.Z., R.M., G.F.F. and C.C. reviewed and edited the manuscript. All authors have read and agreed to the published version of the manuscript.

Funding: The APC was funded by National Natural Science Foundation of China (NSFC-31972868).

Institutional Review Board Statement: This study was authorized by the Italian Ministry of the Environment (Ministero dell'Ambiente e della Tutela del Territorio e del Mare, PNM prot. n.56097/TA31 of 13/11/2017 and integration, prot. n. 7513 of 17/02/2020).

Informed Consent Statement: Not applicable.

Data Availability Statement: Data analysed in this study can be found at this link https:/ / figshare. com/s/387b39c7de65dfc32298.

Acknowledgments: This study was conducted under the auspices of the Chinese Cavefish Working Group. Enrico Lunghi is supported by the Chinese Academy of Sciences President's International Fellowship Initiative for postdoctoral researchers. Caves' coordinate may be provided upon justified requests.

Conflicts of Interest: The authors declare no conflict of interest.

\section{References}

1. Lanza, B.; Pastorelli, C.; Laghi, P.; Cimmaruta, R. A review of systematics, taxonomy, genetics, biogeography and natural history of the genus Speleomantes Dubois, 1984 (Amphibia Caudata Plethodontidae). Atti. Mus Civ. Stor. Nat. Trieste 2006, 52, 5-135.

2. Lanza, B.; Andreone, F.; Bologna, M.A.; Corti, C.; Razzetti, E. Fauna d'Italia. Amphibia; Calderini: Bologna, Italy, 2006.

3. Chiari, Y.; van der Meijden, A.; Mucedda, M.; Lourenço, J.M.; Hochkirch, A.; Veith, M. Phylogeography of Sardinian cave salamanders (genus Hydromantes) is mainly determined by geomorphology. PLoS ONE 2012, 7, e32332. [CrossRef]

4. Carranza, S.; Romano, A.; Arnold, E.N.; Sotgiu, G. Biogeography and evolution of European cave salamanders, Hydromantes (Urodela: Plethodontidae), inferred from mtDNA sequences. J. Biogeogr. 2008, 35, 724-738. [CrossRef]

5. Lunghi, E.; Cianferoni, F.; Giachello, S.; Zhao, Y.; Manenti, R.; Corti, C.; Ficetola, G.F. Updating salamander datasets with phenotypic and stomach content information for two mainland Speleomantes. Sci. Data 2021, 8, 150. [CrossRef]

6. Lunghi, E.; Giachello, S.; Zhao, Y.; Corti, C.; Ficetola, G.F.; Manenti, R. Photographic database of the European cave salamanders, genus Hydromantes. Sci. Data 2020, 7, 171. [CrossRef] [PubMed]

7. Lanza, B.; Caputo, V.; Nascetti, G.; Bullini, L. Morphologic and genetic studies of the European plethodontid salamanders: Taxonomic inferences (genus Hydromantes). Monogr. Mus. Reg. Sci. Nat. Torino 1995, 16, 1-366.

8. Ficetola, G.F.; Lunghi, E.; Cimmaruta, R.; Manenti, R. Transgressive niche across a salamander hybrid zone revealed by microhabitat analyses. J. Biogeogr. 2019, 46, 1342-1354. [CrossRef] 
9. Ruggi, A.; Cimmaruta, R.; Forti, G.; Nascetti, G. Preliminary study of a hybrid zone between Speleomantes italicus Dunn 1923 and S. ambrosii Lanza 1955 on the Apuan Alps, using RLFP analysis. Ann. Mus. Civ. Stor. Nat. Giacomo Doria Genova 2005, 97, 135-144.

10. Forti, G.; Lanza, B.; Cimmaruta, R.; Nascetti, G. An experiment of artificial syntopy ex situ between Speleomantes italicus (Dunn, 1923) and S. ambrosii ambrosii (Lanza, 1955) (Amphibia, Plethodontidae). Ann. Mus. Civ. Stor. Nat. Giacomo Doria Genova 2005, 97, 123-133.

11. Cimmaruta, R.; Forti, G.; Lucente, D.; Nascetti, G. Thirty years of artificial syntopy between Hydromantes italicus and H. ambrosii ambrosii (Amphibia, Plethodontidae). Amphib.-Reptil. 2013, 34, 413-420. [CrossRef]

12. Lunghi, E.; Guillaume, O.; Blaimont, P.; Manenti, R. The first ecological study on the oldest allochthonous population of European cave salamanders (Hydromantes sp.). Amphib.-Reptil. 2018, 39, 113-119. [CrossRef]

13. Lunghi, E.; Corti, C.; Manenti, R.; Ficetola, G.F. Consider species specialism when publishing datasets. Nat. Ecol. Evol. 2019, 3, 319. [CrossRef] [PubMed]

14. Lunghi, E.; Bruni, G. Long-term reliability of visual implant elastomers in the Italian cave salamander (Hydromantes italicus). Salamandra 2018, 54, 283-286.

15. Crovetto, F.; Romano, A.; Salvidio, S. Comparison of two non-lethal methods for dietary studies in terrestrial salamanders. Wildl. Res. 2012, 39, 266-270. [CrossRef]

16. Lunghi, E.; Giachello, S.; Manenti, R.; Zhao, Y.; Corti, C.; Ficetola, G.F.; Bradley, J.G. The post hoc measurement as a safe and reliable method to age and size plethodontid salamanders. Ecol. Evol. 2020, 10, 11111-11116. [CrossRef] [PubMed]

17. Lunghi, E.; Cianferoni, F.; Ceccolini, F.; Mulargia, M.; Cogoni, R.; Barzaghi, B.; Cornago, L.; Avitabile, D.; Veith, M.; Manenti, R.; et al. Field-recorded data on the diet of six species of European Hydromantes cave salamanders. Sci. Data 2018, 5, 180083. [CrossRef]

18. Lunghi, E.; Romeo, D.; Mulargia, M.; Cogoni, R.; Manenti, R.; Corti, C.; Ficetola, G.F.; Veith, M. On the stability of the dorsal pattern of European cave salamanders (genus Hydromantes). Herpetozoa 2019, 32, 249-253. [CrossRef]

19. Lunghi, E.; Cianferoni, F.; Ceccolini, F.; Veith, M.; Manenti, R.; Mancinelli, G.; Corti, C.; Ficetola, G.F. What shapes the trophic niche of European plethodontid salamanders? PLoS ONE 2018, 13, e0205672. [CrossRef] [PubMed]

20. Ficetola, G.F.; Lunghi, E.; Canedoli, C.; Padoa-Schioppa, E.; Pennati, R.; Manenti, R. Differences between microhabitat and broad-scale patterns of niche evolution in terrestrial salamanders. Sci. Rep. 2018, 8, 10575. [CrossRef]

21. Schielzeth, H.; Dingemanse, N.J.; Nakagawa, S.; Westneat, D.F.; Allegue, H.; Teplitsky, C.; Réale, D.; Dochtermann, N.A.; Garamszegi, L.Z.; Araya-Ajoy, Y.G. Robustness of linear mixed-effects models to violations of distributional assumptions. Methods Ecol. Evol. 2020, 11, 1141-1152. [CrossRef]

22. Labocha, M.K.; Schutz, H.; Hayes, J.P. Which body condition index is best? Oikos 2014, 123, 111-119. [CrossRef]

23. Băncilă, R.I.; Hartel, T.; Băncilă, R.I.; Smets, J.; Cogălniceanu, D. Comparing three body condition indices in amphibians: A case study of yellow-bellied toad Bombina variegata. Amphib.-Reptil. 2010, 31, 558-562. [CrossRef]

24. Lunghi, E.; Manenti, R.; Mulargia, M.; Veith, M.; Corti, C.; Ficetola, G.F. Environmental suitability models predict population density, performance and body condition for microendemic salamanders. Sci. Rep. 2018, 8, 7527. [CrossRef] [PubMed]

25. Lunghi, E.; Manenti, R.; Ficetola, G.F. Seasonal variation in microhabitat of salamanders: Environmental variation or shift of habitat selection? PeerJ 2015, 3, e1122. [CrossRef]

26. Salvidio, S.; Romano, A.; Oneto, F.; Ottonello, D.; Michelon, R. Different season, different strategies: Feeding ecology of two syntopic forest-dwelling salamanders. Acta Oecol. 2012, 43, 42-50.

27. Lunghi, E.; Manenti, R.; Cianferoni, F.; Ceccolini, F.; Veith, M.; Corti, C.; Ficetola, G.F.; Mancinelli, G. Interspecific and interpopulation variation in individual diet specialization: Do environmental factors have a role? Ecology 2020, 101, e03088. [CrossRef]

28. Manenti, R.; Lunghi, E.; Ficetola, G.F. Distribution of spiders in cave twilight zone depends on microclimatic features and trophic supply. Invertebr. Biol. 2015, 134, 242-251. [CrossRef]

29. Lunghi, E.; Ficetola, G.F.; Zhao, Y.; Manenti, R. Are the neglected Tipuloidea crane flies (Diptera) an important component for subterranean environments? Diversity 2020, 12, 333. [CrossRef]

30. Lunghi, E.; Cianferoni, F.; Ceccolini, F.; Zhao, Y.; Manenti, R.; Corti, C.; Ficetola, G.F.; Mancinelli, G. Same diet, different strategies: Variability of individual feeding habits across three populations of Ambrosi's cave salamander (Hydromantes ambrosii). Diversity 2020, 12, 180. [CrossRef]

31. Pierson, T.W.; Fitzpatrick, B.M.; Camp, C.D. Genetic data reveal fine-scale ecological segregation between larval plethodontid salamanders in replicate contact zones. Evol. Ecol. 2021, 35, 309-322. [CrossRef]

32. Gargiulo, R.; Kull, T.; Fay, M.F. Effective double-digest RAD sequencing and genotyping despite large genome size. Mol. Ecol. Resour. 2021, 21, 1037-1055. [CrossRef] [PubMed]

33. Lunghi, E.; Manenti, R.; Canciani, G.; Scarì, G.; Pennati, R.; Ficetola, G.F. Thermal equilibrium and temperature differences among body regions in European plethodontid salamanders. J. Therm. Biol. 2016, 60, 79-85. [CrossRef] [PubMed]

34. Markle, T.M.; Kozak, K.H. Low acclimation capacity of narrow-ranging thermal specialists exposes susceptibility to global climate change. Ecol. Evol. 2018, 8, 4644-4656. [CrossRef]

35. Vieites, D.R.; Min, M.-S.; Wake, D.B. Rapid diversification and dispersal during periods of global warming by plethodontid salamanders. Proc. Natl. Acad. Sci. USA 2007, 104, 19903-19907. [CrossRef] [PubMed] 